Eur. J. Clin. Chem. Clin. Biochem.

Vol. 31, 1993, pp. 353-358

(C) 1993 Walter de Gruyter \& Co.

Berlin - New York

\title{
Potential Clinical Use of the EDTA-Infusion Test
}

\author{
By B. Ahrén and A. Bergenfelz
}

Department of Surgery, Lund University, Lund, Sweden

(Received November 13, 1992/March 11, 1993)

Summary: The introduction of assays for the intact parathyrin (parathyroid hormone) has dramatically improved the diagnosis and follow-up of patients with primary hyperparathyroidism. However, in some patients with mild or intermittent hypercalcaemia, when plasma concentrations of intact parathyrin may be within the normal reference concentrations, the diagnosis of primary hyperparathyroidism may still be problematic. In these patients, the EDTA-infusion test is of potential value, as it also might be in patients with equivocal operative findings.

\section{Definition and Diagnosis of Primary Hyperparathyroidism}

Primary hyperparathyroidism is characterized by increased secretion of parathyrin (parathyroid hormone) in combination with increased parathyroid parenchymal cell mass. In primary hyperparathyroidism the secretion of parathyrin is higher than that required for the maintenance of normocalcaemia, which leads to manifest hypercalcaemia. The biochemical diagnosis of primary hyperparathyroidism, therefore, consists in demonstrating hypercalcaemia in combination with a relative or absolute increase in plasma concentrations of parathyrin.

\section{Hypocalcaemia Provocation Tests}

The demonstration of increased plasma concentration of parathyrin is vital for the differential diagnosis of primary hyperparathyroidism from hypercalcaemia due to other diseases. This used to be a clinical problem, since the radioimmunological assays used for the determination of parathyrin also measured fragments of the hormone, the concentration of which exceed that of the intact hormone (1). Other tests were therefore introduced and initially held to be of value in the diagnosis of primary hyperparathyroidism - e.g., determination of urinary excretion of calcium, hydroxyproline or cyclic AMP, measurement of the urinary chloride to phosphate ratio or of the circulating concentrations of vitamin D metabolites or osteocalcin. These tests have failed, however, to contribute any useful diagnostic information (2). Similarly, venous catheterization for measurement of the local concentration of parathyrin has not been found to be of diagnostic value, although such a procedure might be of use in the preoperative localization of the enlarged parathyroid gland (3). To improve the diagnosis of primary hyperparathyroidism other tests seemed to be required, and hypocalcaemia provoca= tion tests were developed. In these tests, hypocalcaemia is induced, which in turn stimulates parathyrin secretion. The hypocalcaemia was induced by calcitonin or EDTA (ethylenediamine tetraacetate) $(4-6)$.

The theoretical basis for the hypocalcaemia provocation tests is the inverse S-shaped relationship between the extracellular concentration of calcium and parathyrin secretion (fig. 1 (7)). The basis for this relation is the activation by extracellular calcium of a membrane-bound receptor in the parathyroid cells (fig. 2). This leads to opening of receptor-operated 


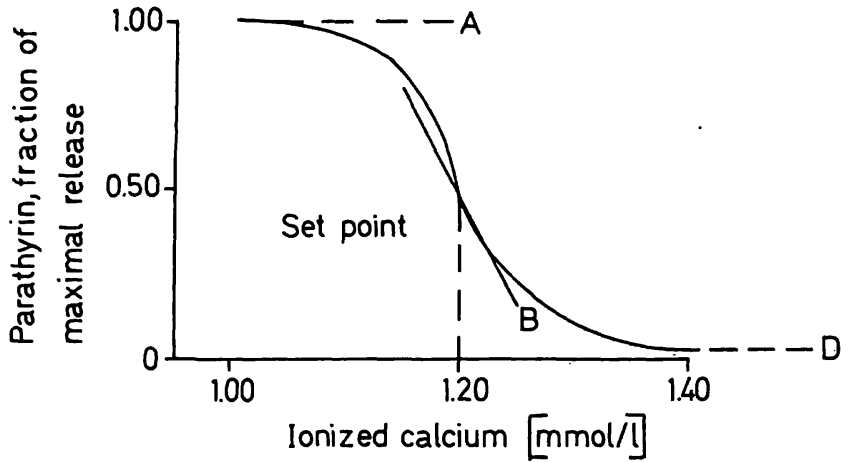

Fig. 1. The relation between the extracellular concentration of ionized calcium and the secretion of parathyrin. The inverse, $\mathrm{S}$-shaped relation is mathematically described by a 4-quantity relation involving the quantities $\mathrm{A}, \mathrm{B}$, $\mathrm{D}$ and the "set point". For a detailed explanation see the text.

membrane-bound calcium channels, which leads in turn to uptake of extracellular calcium. Activation of the calcium receptor also initiates phosphoinositide hydrolysis, resulting in formation of inositol-1,4,5trisphosphate, with the subsequent liberation of calcium from intracellular calcium storage sites. Both these processes increase the cytoplasmic concentration of calcium, which is followed by inhibition of the parathyrin secretion. Conversely, during hypocalcaemia the intracellular calcium concentration is reduced, which stimulates parathyrin secretion.
Figure 1 shows that the steepest part of the relation between extracellular calcium and parathyrin secretion is close to the calcium concentration that inhibits the parathyrin secretion by $50 \%$. This calcium value is called the "set point", and it is close to the concentration of plasma ionized calcium that is normally seen (8). The curvilinear relation between calcium and parathyrin has been characterized by four different quantities, as shown in figure 1. Quantity $\mathrm{A}$ is the maximal parathyrin secretion obtained during hypocalcaemia, whereas quantity $\mathrm{D}$ is the minimal secretion seen after maximal hypercalcaemia. Quantity C is the "set point" and quantity B is a quantity related to the slope of the curve at the "set point". The secretion of parathyrin (i. e., Y) is dependent on the extracellular calcium (i. e., $\mathrm{X}$ ) according to the relation $\mathrm{Y}=\mathrm{A}-\mathrm{D} /\left[1+(\mathrm{X} / \mathrm{C})^{\mathrm{B}}\right]+\mathrm{D}(7)$.

\section{Changes in the Calcium-Parathyrin-Relation in Pri- mary Hyperparathyroidism}

The normal relation between extracellular calcium and parathyrin secretion is altered in patients with primary hyperparathyroidism, since calcium does not normally inhibit parathyrin secretion. There exists evidence that this defective sensitivity to calcium is due to a down-regulation of the calcium receptor in the parathyroid cell (9). Thus, to obtain a sufficiently

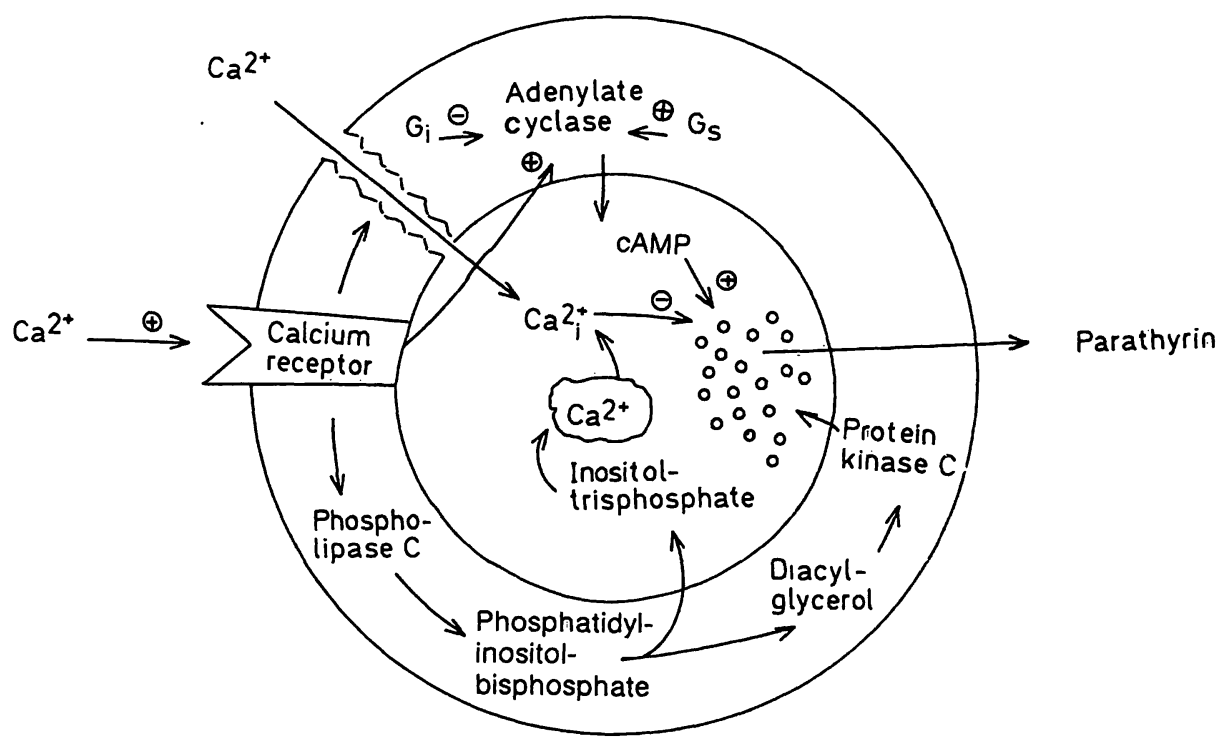

Fig. 2. Cell-biological processes involved in the regulation of the secretion (exocytosis) of parathyrin in the parathyroid cell. Extracellular calcium activates a specific, membrane-bound, calcium receptor which leads to opening of receptor-operated calcium channels, activation of phospholipase C and inhibition of adenylate cyclase with reduced formation of cAMP. The opening of the calcium channel leads to the uptake of extracellular calcium, whereas activation of phospholipase $C$ leads to hydrolysis of membrane-bound phosphoinositide bisphosphate with the formation of inositol-1,4,5-trisphosphate and diacyl glycerol. Inositol-1,4,5-trisphosphate in turn stimulates the release of calcium from intracellular storage sites which, together with the uptake of calcium, leads to increased concentration of cytoplasmic calcium. This, in turn, inhibits the exocytosis of parathyrin. Diacyl glycerol activates protein kinase $C$, which affects the exocýtosis, and cAMP stimulates G-proteins. 
high intracellular calcium concentration to induce inhibition of parathyrin secretion, a higher extracellular concentration of calcium is required in primary hyperparathyroidism than under normal conditions. Consequently, a patient with primary hyperparathyroidism has a right-shifted relation between extracellular calcium and parathyrin secretion when compared to a healthy individual, i. e., primary hyperparathyroidism is associated with an increased "set point" (fig. 3).

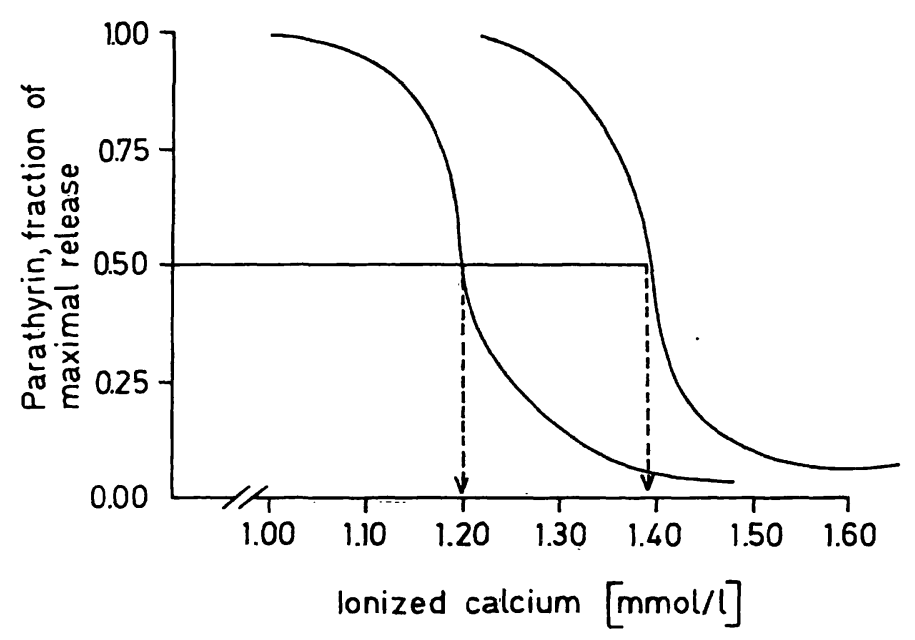

Fig. 3. The right-shifted inverse S-shape releationship between extracellular calcium and the parathyrin secretion in patients with primary hyperparathyroidism (right curve) compared with healthy subjects (left curve).

By reducing the extracellular calcium concentration, by means of calcitonin or EDTA, and by measuring the plasma parathyrin concentrations, the highest concentration of calcium that stimulates the parathyrin secretion can be measured: in primary hyperparathyroidism this occurs at calcium concentrations exceeding the upper reference concentration for normality. In contrast, in patients with hypercalcaemia due to other causes, parathyrin secretion is not stimulated until the calcium concentration has dropped to concentrations within the normal range. The hypocalcaemia provocation tests, therefore, are able to distinguish hypercalcaemic patients with primary hyperparathyroidism from those with malignancy, for example $(4-6)$.

\section{Intact Parathyrin}

In the late 1980s new immunoradiometric and immunochemilunometric assays for the determination of parathyrin were introduced. These assays measure intact parathyrin without interfering with inactive parathyrin fragments (10). With these assays an almost complete separation is established between hypercalcaemic patients with primary hyperparathyroidism and those with malignancy (10). By the use of these new assays for intact parathyrin, the need for hypocalcaemia-provocation tests in the diagnosis of primary hyperparathyroidism initially seemed to be eliminated. However, it has been established that the new assays for intact parathyrin can not completely separate patients with primary hyperparathyroidism from normal individuals (10). This has been explained by the high sensitivity of the tests, since parathyrin secretion under normal conditions is pulsatile with a circadian variation (11). Therefore, the concentration of intact parathyrin might occassionally be normal in a patient with primary hyperparathyroidism. This might present a particular diagnostic problem in patients with mild or intermittent hypercalcaemia, since there is a correlation between the calcium concentration and the intact parathyrin concentration (12). In such cases, a hypocalcaemia provocation test might be useful.

\section{EDTA-Infusion Test}

We undertake the EDTA-infusion test followed an overnight fast with the patient placed in a recumbent position. An antecubital catheter is inserted on both sides. From one catheter blood samples are taken regularly, whereas the infusions are given through the other catheter. Six $\mathrm{g} \mathrm{Na} \mathrm{ND}_{2} \mathrm{EDA}$ are dissolved in 250 $\mathrm{ml}$ saline and infused intravenously with a constant infusion rate of $24 \mathrm{mg} / \mathrm{h} \cdot \mathrm{kg}$ body weight, i. e., by 1.0 $\mathrm{ml} / \mathrm{h} \cdot \mathrm{kg}$. During the infusion, local discomfort or pain might be felt in the arm, sometimes radiating to the shoulder. This pain is reduced by infusing lidocain. We dissolve $200 \mathrm{mg}$ lidocain in $250 \mathrm{ml}$ saline and infuse up to $20 \mathrm{ml} /$ hour. We have found that the local discomfort is usually prevented by preinfusing lidocain at the rate of $10 \mathrm{ml} /$ hour before starting the EDTA infusion.

EDTA is infused for 70 minutes. Before, during, and after the infusion, blood samples are taken every 10 minutes. One sample is taken anaerobically in preheparinised tubes for the determination of ionized calcium, whereas another sample is taken for the analyses of intact parathyrin. Before the test, the kidney function needs to be estimated, since in the case of kidney damage, the infusion of EDTA might be hazardous. We therefore routinely analyse the serum concentration of creatinine in all cases before the EDTA infusion test. No other precautions are required, however. 


\section{Results of EDTA-Infusion-Tests}

We have shown in a previous paper (13) that, when using an EDTA-infusion test in the diagnosis of primary hyperparathyroidism, determination of intact parathyrin is superior to that of the mid-molecule Cterminal parathyrin. We showed that in 15 patients with primary hyperparathyroidism the concentration of intact parathyrin rose by $240 \%$ during the EDTA infusion test, whereas the concentration of mid-molecule C-terminal parathyrin rose by only $65 \%$ $(\mathrm{P}<0.01)$. Furthermore, in four patients with primary hyperparathyroidism, the concentration of midmolecule C-terminal parathyrin did not rise at all during the EDTA infusion, while the concentration of intact parathyrin rose significantly in these patients. Intact parathyrin should, therefore, be determined when using EDTA-infusion tests.

Figure 4 shows the result of the EDTA-infusion test in a healthy subject compared with that in a patient with primary hyperparathyroidism. As is seen in the upper panel of the figure, the concentration of ionized calcium is reduced by approximately $0.15 \mathrm{mmol} / 1$ during the 70 min EDTA-infusion test, and the middle panel of the figure shows that the concentration of

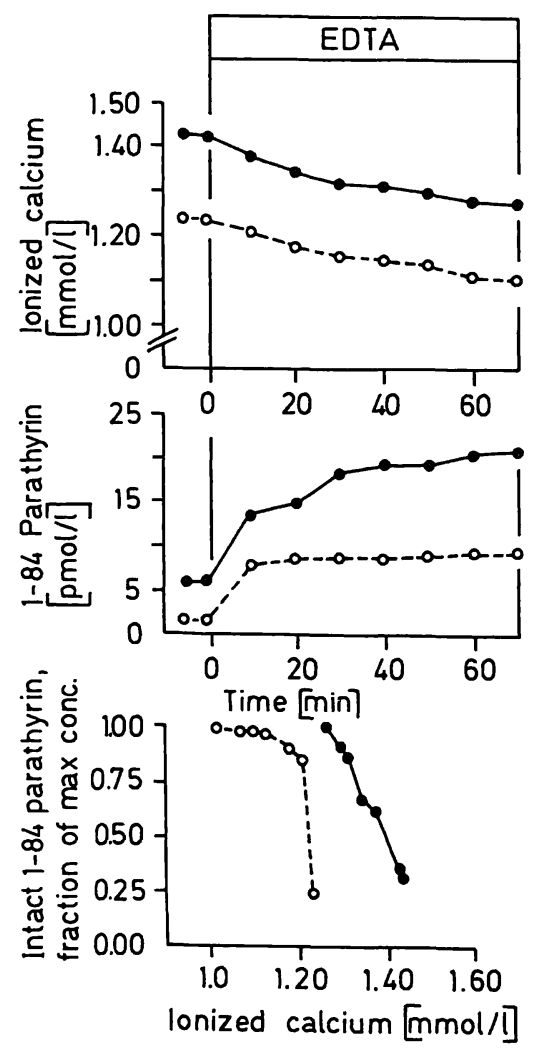

Fig. 4. Serum concentration of ionized calcium (upper panel) and plasma concentration of intact parathyrin (middle panel) before, during and after the 70 min EDTAinfusion test in a patient with primary hyperparathyroidism $(\bullet-\bullet)$ and in a healthy subject $(0 \cdots--0)$. The lower panel shows the values transformed into a calcium-parathyrin-relation-curve. intact parathyrin is increased in both individuals. In the patient with primary hyperparathyroidism, the plasma concentration of intact parathyrin already starts to rise when the concentration of ionized calcium approaches $1.35 \mathrm{mmol} / \mathrm{l}$ (the upper reference value is $1.29 \mathrm{mmol} / \mathrm{l}$ ), whereas the corresponding calcium value in the healthy subject is $1.21 \mathrm{mmol} / \mathrm{l}$. This difference illustrates the increased "set point" in patients with primary hyperparathyroidism and is diagnostic for the disease. The lower panel of the figure shows the values in these individuals transformed to a calcium-parathyrin-relation-curve. The right-shifted relation in the patient with primary hyperparathyroidism compared with the healthy individual is clearly illustrated.

The interpretation of the EDTA-infusion test is more difficult in patients with mild hypercalcaemia with only a slightly increased "set point". Figure 5 shows such a patient. The figure shows the concentration of intact parathyrin in relation to the concentration of ionized calcium during and immediately after the EDTA-infusion test. It can be seen that when the plasma concentration of intact parathyrin starts to rise the concentration of ionized calcium is within the normal reference values. It is, however, known that when the calcium concentration is changed very slowly or not at all, as is the case in the sample taken immediately after the end of the EDTA-infusion test, the concentration of intact parathyrin shows its closest correlation to the absolute calcium concentration (14). Thus, the diagnostic efficiency is highest when the concentration of intact parathyrin is interpreted in the samples taken immediately after the end of the infusion of EDTA: if intact parathyrin concentrations then are raised and the calcium concentration is normal, the patient has primary hyperparathyroidism, whereas if intact parathyrin is within normal concentrations, the patient does not have primary hyperparathyroidism (12). The patient in figure 5, therefore, has

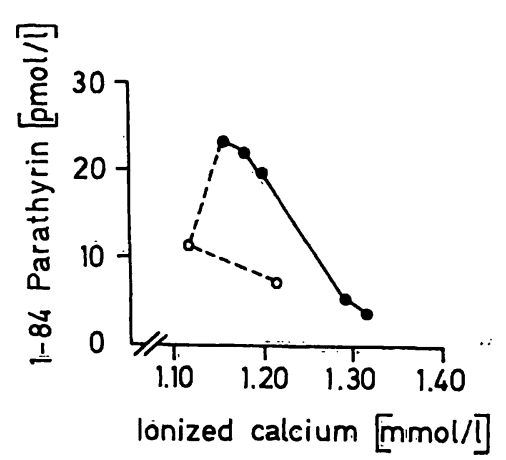

Fig. 5. The relation between the plasma concentration of intact parathyrin and the serum coincentration of calcium during $(\bullet-\bullet)$ and immediately after $(0----0)$ the EDTAinfusion test in a patient with mild primary hyperparathyroidism. 
primary hyperparathyroidism, since intact parathyrin in the last sample is $7.4 \mathrm{pmol} / \mathrm{l}$ (upper reference value $5.0 \mathrm{pmol} / \mathrm{l})$, whereas the ionized calcium concentration is normal $(1.22 \mathrm{mmol} / \mathrm{l})$.

\section{The Use of the EDTA-Infusion Test in the Diagnosis of Primary Hyperparathyroidism}

To distinguish hypercalcaemic patients with primary hyperparathyroidism from those with malignancy, determination of the basal concentration of intact parathyrin is usually sufficient (10). The clinical problem today is distinguishing patients with mild primary hyperparathyroidism from normal individuals. These patients have mild, or even only intermittent, hypercalcaemia, but the basal concentration of intact parathyrin is within the normal limits. They may or may not be symptomatic. Recent studies have suggested that this patient group is not small (15). The EDTAinfusion test might be diagnostic in these patients. Hence, even though the introduction of assays for intact parathyrin has markedly improved the diagnostic accuracy for primary hyperparathyroidism, there is still a need for hypocalcaemia provocation tests in a subgroup of patients with primary hyperparathyroidism.

We recently examined the value of intact parathyrin in 26 consecutive patients with hypercalcaemia and suspected primary hyperparathyroidism, of whom all except one at operation also were demonstrated to have the disease (12). We used a commercially available immunoradiometric assay for intact parathyrin with an inter-assay variation of $<10 \%$ and an intraassay variation of $<6 \%$, when expressed as coefficients of variation. We found that in six of the 25 cases shown to have primary hyperparathyroidism, the intact parathyrin concentration was within the normal range. This high incidence of patients with normal concentrations of intact parathyrin is in agreement with a recent study (10), but in contrast with earlier reports where the incidence of primary hyperparathyroidism with normal intact parathyrin con- centrations was lower. A likely explanation for this differences would be different selections of patients in different studies. In five of our cases with normal values of intact parathyrin we performed the EDTAinfusion test. The test was positive, i.e., diagnostic for primary hyperparathyroidism, in all five patients, who at operation were shown to have the disease. Thus, our experience is that the EDTA-infusion test is of diagnostic value in this subset of patients with suspected primary hyperparathyroidism.

\section{The EDTA-Infusion Test in the Follow-up of Patients with Primary Hyperparathyroidism}

Both molecular biological (16) and functional (17) studies have presented evidence that parathyroid adenomas are of monoclonal origin and that, therefore, the non-adenomatous glands are normal. This indicates that the "set point" should not be raised postoperatively in patients with adenomas, as we have demonstrated as well (17). Hence, in patients operated on for primary hyperparathyroidism but who have equivocal operative findings, a postoperative EDTAinfusion test could be of clinical value. If the postoperative "set point" is not raised, it can be concluded that the operation has been a success.

\section{Conclusion}

Our review has shown that, despite the introduction of sensitive assays for intact parathyrin, there is a need for an EDTA-infusion test in a subset of patients with suspected primary hyperparathyroidism, mainly in those with mild or intermittent hypercalcaemia and a normal basal concentration of intact parathyrin.

\section{Acknowledgement}

The studies by the authors have been supported by the Swedish Medical Research Council, the Greta and Johan Kocks Foundation, and the Faculty of Medicine, Lund University.

\section{References}

1. Armitage, E. K. (1986) Parathyrin (parathyroid hormone): metabolism and methods for assay. Clin. Chem. 32, 418424.

2. Marcus, R. (1989) Laboratory diagnosis of primary hyperparathyroidism. In: Endocrinology and Metabolism Clinics of North America: Hypercalcemia (Marcus, R., ed.) W. B. Saunders, Philadelphia, pp. 647-658.

3. Bergenfelz, A., Lundstedt, C., Stridbeck, H. \& Ahrén, B. (1992) Large vein sampling for intact parathyroid hormone in preoperative localization of enlarged parathyroid glands. Acta Radiol. 33, 528-531.
4. Benson, L., Wide, L., Åkerström, G. \& Ljunghall, S. (1984) A stimulation test with calcitonin for differential diagnosis of hypercalcemia. Acta Endocrinol. 107, 237-244.

5. Ljunghall, S., Benson, L., Rastad, J., Wide, L. \& Akerström, G. (1987) Dynamic tests of parathyroid function for diagnosis of primary hyperparathyroidism in malignancy. Clin. Endocrinol. 27, 163-170.

6. Benson, L., Rastad, J., Wide, L., Åkerström, G. \& Ljunghall, S. (1986) Stimulation of parathyroid hormone secretion by EDTA infusion - A test for the differential diagnosis of hypercalcemia. Acta Endocrinol. 111, 498-506. 
7. Brown, E. M. (1983) Four-parameter model of the sigmoidal relationship between parathyroid hormone release and extracellular calcium concentration in normal and abnormal parathyroid tissue. J. Clin. Endocrinol. Metab. 56, $572-581$.

8. Brent, G. A., LeBoff, M. S., Seely, E. W., Conlin, P. R. \& Brown, E. M. (1988) Relationship between the concentration and rate of change of calcium and serum intact parathyroid hormone levels in normal humans. J. Clin. Endocrinol. Metab. 67, 944-950.

9. Nygren, P., Gylfe, E., Larsson, R., Johansson, H., Juhlin, C., Akerström, G. \& Rastad, J. (1988) Modulation of the $\mathrm{Ca}^{2+}$-sensing function of parathyroid cells in vitro and in hyperparathyroidism. Biochim. Biophys. Acta 968, 253260.

10. Endres, D. B., Villanueva, R., Sharp Jr, C. F. \& Singer, F. R. (1991) Immunochemiluminometric and immunoradiometric determination of intact and total immunoreactive parathyrin: performance in the differential diagnosis of hypercalcemia and hypoparathyroidism. Clin. Chem. 37, $162-168$.

11. Kitamura, N., Shigeno, C., Shiomi, K., Lee, K., Ohta, S., Sone, T., Katsushima, S., Tadamura, E., Kousaka, T., Yamamoto, I., Dokoh, S. \& Konishi, J. (1990) Episodic fluctuation in serum intact parathyroid hormone concentration in men. J. Clin. Endocrinol. Metab. 70, 252-263.
12. Bergenfelz, A., Valdemarsson, S. \& Ahrén, B. (1991) Measurement of intact parathyroid hormone in the diagnosis of hyperparathyroidism. Acta Endocrinol. 125, 668-674.

13. Bergenfelz, A., Nordén, N. E. \& Ahrén, B. (1991) Intact parathyroid hormone assay is superior to mid region assay in the EDTA-infusion test in hyperparathyroidism. Clin. Chim. Acta 197, 229-235.

14. Grant, F. D., Conlin, P. R. \& Brown, E. M. (1990) Rate and concentration dependence of parathyroid hormone dynamics during stepwise changes in serum ionized calcium in normal humans. J. Clin. Endocrinol. Metab. 71, 370378.

15. Heath III, H., Hodgson, S. F. \& Kennedy, M. A. (1980) Primary hyperparathyroidism. Incidence, morbidity and potential economic impact in a community. N. Engl. J. Med. 302, 189-193.

16. Arnold, A., Staunton, C. E., Kim, H. G., Gaz, R. D. \& Kronenberg, H. M. (1988) Monoclonality and abnormal parathyroid hormone genes in parathyroid adenomas. $\mathrm{N}$. Engl. J. Med. 318, 658-662.

17. Bergenfelz, A., Nordén, N. E. \& Ahrén, B. (1993) Parathyroid hormone secretion after operation for primary hyperparathyroidism. Surgery in press.

Dr. Bo Ahrén

Department of Surgery

Lund University

S-221 85 Lund

Sweden 